\title{
Should computed tomography and bronchoscopy be routine examinations for chronic cough?
}

\author{
Li Yu, Xianghuai Xu, Shanshan Niu \\ Department of Pulmonary and Critical Care Medicine, Tongji Hospital, Tongji University School of Medicine, Shanghai, China \\ Contributions: (I) Conception and design: L Yu; (II) Administrative support: L Yu; (III) Provision of study materials or patients: All authors; (IV) \\ Collection and assembly of data: All authors; (V) Data analysis and interpretation: L Yu; (VI) Manuscript writing: All authors; (VII) Final approval of \\ manuscript: All authors. \\ Correspondence to: Li Yu. Department of Pulmonary and Critical Care Medicine, Tongji Hospital, Tongji University School of Medicine, Shanghai \\ 200065, China. Email: yuli0219@sina.com.
}

\begin{abstract}
Chronic cough is a common symptom of many diseases. Guidelines on cough from different countries recommend chest $\mathrm{X}$-ray as the first-line examination. However, as compared to computerized tomography (CT), chest X-ray is insensitive in the diagnosis of many diseases. We speculate that CT is more helpful in excluding the causes of long-term cough, such as bronchial tumors and pulmonary interstitial diseases, which prevents patients from receiving unnecessary examinations and diagnostic treatments for chronic cough. In addition, a single chest CT is safe and affordable in some regions. Therefore, chest CT may be recommended as a first-line examination for patients with chronic cough. In addition, although bronchoscopy is employed as a further examination for chronic cough, it plays an important role in the diagnosis of chronic cough, especially in rare bronchial diseases such as amyloidosis and foreign body inhalation. Induced sputum cytology was not accepted as a necessary examination for chronic cough, but it becomes a first-line examination until physicians recognize that non-asthmatic eosinophilic bronchitis is a common cause of chronic cough. Therefore, we speculate that the roles of chest CT and bronchoscopy in the identification of causes of chronic cough are increasingly important; in some regions, or for patients suspicious for uncommon causes of chronic cough, CT and bronchoscopy are recommended as first-line examinations.
\end{abstract}

Keywords: Chronic cough; chest X-ray; computerized tomography (CT); bronchoscopy

Submitted Feb 24, 2020. Accepted for publication Sep 06, 2020.

doi: $10.21037 /$ jtd-2020-icc-001

View this article at: http://dx.doi.org/10.21037/jtd-2020-icc-001

\section{Introduction}

Chronic cough is a common symptom of some diseases, and the accurate identification of the specific causes of chronic cough is crucial for the successful treatment. Current guidelines from different countries recommend chest X-ray (CXR) and lung function test as first-line examinations. However, whether chest computerized tomography (CT) and bronchoscopy may be employed as routine or preferred tests in the identification of causes of chronic cough is still poorly understood. We speculate that chest CT may be used as a routine examination, and bronchoscopy is also extremely important in the diagnosis of causes of chronic cough.

\section{Status of chest CT}

In the guidelines of various countries, chronic cough patients refer to those with cough lasting no less than 8 weeks and normal CXR findings (1-4). The guideline of European Respiratory Society published in 2004 states that it is not cost-effective to include high-resolution chest CT in the baseline examinations of causes of chronic cough (5). Similarly, the guideline of American College of Chest Physicians recommends chest CT only when the 
most common causes of chronic cough are excluded (6). However, the recent guideline of European Respiratory Society shows that the a very low evidence level of CT recommended as the preferred examination (4). Thus, whether chest CT should be employed as the preferred examination in the identification of causes of chronic cough is unclear. We discuss this issue as follows:

\section{Advantages of chest CT}

\section{Diagnostic advantages for lung diseases}

Undoubtedly, chest CT is more useful than CXR in diagnosing uncommon pulmonary conditions, such as mediastinal or hilar mass, lymphadenopathy, intraluminal lesions of the trachea and/or bronchia, early-stage interstitial lung disease, bronchiectasis, pericardial diseases and others.

Paioli et al. enrolled 215 patients aged over 40 years who had lung metastases alone as first pattern of recurrence after treatment for extremity osteosarcoma. The patients were followed up with CXR or chest CT for a median of 47 months (1-300 months). Their results showed the relapse-free interval was longer and the portion of patients with relapse-free interval $<2$ years was lower in the CXR group, which means that the disease condition in the CXR group was better than in the CT group. However, the second complete remission rate was lower in patients followed up by CXR (60\%) than in those followed up by chest CT (88\%). Five-year post relapse survival and overall survival were significantly lower in the CXR group than in the CT group. Finally, the investigators concluded that follow-up with chest CT led to a better prognosis (7).

Sometimes, CXR may make mistakes. Self et al. investigated 3,423 patients from 12 different emergency departments in the United States who received both CXR and chest CT. $73.1 \%$ of patients who had abnormal CXR findings had normal chest CT. 108 (3.5\%) patients with normal CXR findings were found to have lung shadows on chest CT. For patients who have abnormal CXR findings, the majority of patients suffered twice radiations to confirm their normality, while the patients who have normal CXR findings have the risk of false negative, leading to the delayed treatment (8).

Since the chest CT has significant advantages over CXR, why do different guidelines recommend CXR as a routine examination of chronic cough instead of chest CT? In the cough guideline developed by the European Respiratory Society in 2020 (4), chest CT is not routinely recommended in patients with chronic cough who have normal findings on CXR and physical examination, but the level of evidence on this recommendation is very low. Currently, clinical evidence is insufficient to confirm that CXR is enough to exclude pulmonary abnormalities. The common causes of chronic cough, such as cough variant asthma, upper airway cough syndrome, non-asthmatic eosinophilic bronchitis, and gastroesophageal reflux-induced chronic cough, are often confirmed on the basis of absence of lung abnormalities. Therefore, we speculate that chest CT may be employed as a routine examination for chronic cough patients, which is more conducive to exclude lung diseases, rather than chest CT performed after CXR.

In some cases of chronic cough, such as IgG4 related fibrosing mediastinitis, tracheobronchopathia osteochondroplastica, tracheobronchial amyloidosis, pulmonary lymphangitic carcinomatosis, and thoracic aortic aneurysm, the abnormalities can't be identified on CXR, and CT is often needed for the diagnosis (9-13). Of course, above causes account for a minority and do not represent the majority of cases.

In a study about the etiology of chronic cough, McGarvey et al. retrospectively reviewed 124 patients presenting with chronic cough. They found that CXR was helpful in establishing the cause of chronic cough in only $31 \%$ of cases, while chest CT identified pulmonary abnormalities in $59 \%$ of cases. Of note, the chest CT revealed pulmonary abnormalities in $28 \%$ of cases with normal CXR findings (14). Palombini $e t a l$. prospectively studied 78 non-smokers with cough who have normal CXR findings. Chest CT was performed in 64 patients and revealed the potential cause of chronic cough in $24 \%$ of cases. The positive predictive value of high-resolution chest CT was $83 \%$, and negative predictive value $100 \%$. Thus, we speculate that highresolution chest $\mathrm{CT}$ is more cost-effective (15).

Similarly, Chang et al. investigated more than 300 children with chronic cough, and they found the negative predictive value of CXR in the diagnosis of specific cough was as low as $15 \%(16)$.

In a recent study, Truba $e t$ al. retrospectively analyzed 59 non-smokers with chronic cough, who received both CXR and chest CT. Results showed $95 \%$ of patients with normal CXR findings had abnormalities in the lung, mediastinum, or thorax on chest CT; these abnormalities in $36 \%$ of patients were confirmed to be associated with chronic cough, including bronchiectasis, mediastinal lymphadenopathy, and interstitial lung disease. Because some patients have no abnormalities on the CXR, examinations such as bronchial provocation test, sputum induction, and multichannel 
Table 1 Cost between chest X-ray and CT in different cities of China

\begin{tabular}{|c|c|c|c|}
\hline \multirow{2}{*}{ Location } & \multicolumn{2}{|l|}{ Cost ( $¥)$} & \multirow{2}{*}{$\begin{array}{l}\text { Ratio of } \mathrm{CT} / \text { chest } \\
\text { radiography }\end{array}$} \\
\hline & Chest radiography & CT & \\
\hline Shanghai & 70 & 170 & 2.4 \\
\hline Beijing & 136 & 277 & 2.0 \\
\hline Hangzhou & 107 & 243 & 2.3 \\
\hline Shenzhen & 128 & 400 & 3.1 \\
\hline Shanxi & 240 & 629 & 2.6 \\
\hline Taizhou, Zhejiang & 54 & 222 & 4.1 \\
\hline Tongling, Anhui & 151 & 241 & 1.6 \\
\hline Yinchuang & 80 & 219 & 2.7 \\
\hline Heze, Shandong & 117 & 220 & 1.9 \\
\hline Hefei & 104 & 227 & 2.2 \\
\hline Qinhuangdao & 160 & 308 & 1.9 \\
\hline Wenzhou & 35 & 130 & 3.7 \\
\hline Taizhou & 43 & 188 & 4.4 \\
\hline Zibo & 120 & 300 & 2.5 \\
\hline Yixing & 82 & 316 & 3.9 \\
\hline Suzhou & 80 & 221 & 2.7 \\
\hline Lanzhou & 80 & 495 & 6.2 \\
\hline Tianjin & 135 & 560 & 4.1 \\
\hline
\end{tabular}

esophageal impedance-pH monitoring are often performed. Even a series of empirical treatments, including the treatment for refractory cough (such as gabapentin) are employed, which may cause some adverse effects. Earlier resolution of chronic cough through early identification and early etiological treatment would reduce the economic burden associated with recurrent consultations (17).

According to above findings, chest $\mathrm{CT}$ is a more costeffective examination in the diagnosis of causes of chronic cough.

\section{Safety issues of chest CT}

As we all know, the radiation dose of CT is significantly higher than that of CXR. The radiation dose is only 0.01-0.05 $(\mathrm{mSV})$ for of CXR and 1.0-5.0 (mSV) for normal CT (18). Berrington de González et al. investigated the correlation between CT and projected cancer risk in the United States in 2007 (19). They found that $1 / 3$ of projected cancers were ascribed to the CT performed at the age of 35-54 years and $15 \%$ to the CT at the age of $<18$ years old; $66 \%$ of the projected cancers were found in females.

However, with the development of technology, technicians have worked on reducing radiation exposure to reduce the risk of tumors without compromising image quality and diagnostic accuracy $(20,21)$. Hu-Wang et al. employed ultra-low-dose CT to follow up patients with lymphangioleiomyomatosis in which the $6 \mathrm{mGy}$ on normal CT was reduced to $0.3 \mathrm{mGy}$, which is almost equivalent to a CXR (22). According to the American Radiological Association, the yearly radiation exposure should be no more than $50 \mathrm{mSv}$, and the life-long radiation exposure should be no more than $10 \mathrm{mSv} \times$ age, and no more than $5 \mathrm{mSv}$ ( $<10$ screening is safe) for publics. The risk factor of CT is a cumulative dose of radiation, not a single dose. Therefore, as long as the routine CT is not repeatedly performed and low-dose CT is acceptable, the radiation dose is within the safe range and thus CT is suitable for patients with chronic cough.

In addition, the US guidelines for lung cancer recommend low-dose CT to screen lung cancer in high-risk populations, and the use of low-dose CT is also beneficial for the identification of coexisting conditions (23). The asymptomatic high-risk people are the candidates for screening with low-dose CT, and chest CT is also applicable in those who have cough for more than 8 weeks.

As mentioned above, when positive findings are found on CXR, chest CT scan may be performed to confirm the findings, which instead increases the radiation dose. Therefore, we recommend routine chest CT to exclude lung lesions.

\section{Economic concern in some regions}

In some regions, such as mainland China, the cost between CXR and chest CT is similar (Table 1), and thus economic concern may not be an obstacle to perform chest CT. However, the medical cost in the selection of CXR or CT should be taken into account in medicare system of western countries.

In summary, we speculate that CT, especially low-dose CT, should be the preferred examination for chronic cough patients due to its relatively high diagnostic efficiency and comparable safety of CT as compared to CXR.

\section{Role of bronchoscopy in chronic cough}

To date, bronchoscopy has not been recognized as a routine examination for chronic cough. In some cases, such as 
tracheobronchopathia osteochondroplastica, bronchial tuberculosis, and tracheobronchial amyloidosis, which are not common causes of chronic cough, bronchoscopy is often employed to identify the cause of chronic cough $(11,24)$. It seems that it should not be the first line examination for chronic cough.

As is known to all, non-asthmatic eosinophilic bronchitis is not regarded as one of the common causes of chronic cough at the early-stage of studies on chronic cough (25). Therefore, cytological examination after sputum induction is not necessary in the initial identification of causes of chronic cough. When non-asthmatic eosinophilic bronchitis is confirmed as an important and common cause of chronic cough, cytological examination after sputum induction becomes the first line examination for chronic cough patients. In clinical practice, chronic cough of unknown cause is not uncommon. It is estimated that chronic cough of unknown cause accounts for $5-10 \%$, and even up to $46 \%$ in some studies. Thus, in patients with chronic cough of unknown cause, bronchoscopy may be performed (26).

In as early as 1980s, bronchoscopy was not employed in the diagnosis of chronic cough (27). By 2007, Decalmer et al. reported that bronchoscopy revealed abnormalities in $11 \%$ of patients with chronic cough of unknown cause (28). In 2019, Fracchia et al. investigated the role of endoscopy in the diagnosis of chronic cough in 243 children who underwent bronchoscopy, gastroscopy, and laryngoscope; their results showed $67.5 \%$ of children had abnormal bronchoscopical findings (29). These results indicate that increasing patients require bronchoscopy for the identification of cause of chronic cough, and bronchoscopy is likely to become a routine examination for chronic cough patients in the future. At present, more high-quality clinical studies are warranted to confirm the role of bronchoscopy in the diagnosis of chronic cough.

In summary, in order to rule out or confirm common or uncommon causes, reasonable, effective and safe examinations should be conducted as soon as possible. In a few developed areas, the examinations usually have a low cost, and can be easily and quickly performed in hospitals. We speculate that chest CT, especially low-dose CT, can be used as a routine examination for chronic cough patients, while repeated CT examinations are not recommended. For patients in whom the causes of chronic cough remain unclear after routine examinations and those who have no response to the treatment targeting common causes, bronchoscopy should be recommended as a first-line examination.

\section{Acknowledgments}

Funding: This study was supported by the National Natural Science Foundation of China (No. 81770097), the Project of Science and Technology Commission of Shanghai Municipality (No. 17411970800 and 20ZR1451500) and the Fund of Shanghai Municipal Health Commission for Excellent Young Scholars (No. 2018YQ01).

\section{Footnote}

Provenance and Peer Review: This article was commissioned by the Guest Editor (Kefang Lai) for the series "3rd International Cough Conference" published in fournal of Thoracic Disease. The article was sent for external peer review.

Conflicts of Interest: All authors have completed the ICMJE uniform disclosure form (available at http:// dx.doi.org/10.21037/jtd-2020-icc-001). The series "3rd International Cough Conference" was commissioned by the editorial office without any funding or sponsorship. The authors have no other conflicts of interest to declare.

Ethical Statement: The authors are accountable for all aspects of the work in ensuring that questions related to the accuracy or integrity of any part of the work are appropriately investigated and resolved.

Open Access Statement: This is an Open Access article distributed in accordance with the Creative Commons Attribution-NonCommercial-NoDerivs 4.0 International License (CC BY-NC-ND 4.0), which permits the noncommercial replication and distribution of the article with the strict proviso that no changes or edits are made and the original work is properly cited (including links to both the formal publication through the relevant DOI and the license). See: https://creativecommons.org/licenses/by-nc-nd/4.0/.

\section{References}

1. Chinese Medical Association of Respiratory Disease Asthma Study Group. Guideline for diagnosis and treatment of cough. Zhonghua Jie He He Hu Xi Za Zhi 2016;39:323-54.

2. Irwin RS, et al. Classification of Cough as a Symptom in Adults and Management Algorithms: CHEST Guideline and Expert Panel Report. Chest 2018;153:196-209.

3. Song DJ, Song WJ, Kwon JW, et al. KAAACI Evidence- 
Based Clinical Practice Guidelines for Chronic Cough in Adults and Children in Korea. Allergy Asthma Immunol Res 2018;10:591-613.

4. Morice AH, Millqvist E, Bieksiene K, et al. ERS guidelines on the diagnosis and treatment of chronic cough in adults and children. Eur Respir J 2020;55:1901136.

5. Morice AH, Fontana GA, Sovijarvi ARA, et al. ERS Task Force. The diagnosis and management of chronic cough. Eur Respir J 2004;24:481-92.

6. Irwin RS, Baumann MH, Bolser DC, et al. Diagnosis and management of cough executive summary: ACCP evidencebased clinical practice guidelines. Chest. 2006;129:1S-23S.

7. Paioli A, Rocca M, Cevolani L, et al. Osteosarcoma followup: chest X-ray or computed tomography? Clin Sarcoma Res 2017;7:3.

8. Self WH, Courtney DM, McNaughton CD, et al. High discordance of chest $\mathrm{x}$-ray and computed tomography for detection of pulmonary opacities in ED patients: implications for diagnosing pneumonia. Am J Emerg Med 2013;31:401-5.

9. Theofilos D, Triantafillidou C, Zetos A, et al. A 44-YearOld Man with Chronic Cough, Weakness, and a Mediastinum Mass. Chest 2015;148:e86-90.

10. Abouda M, Jomni T, Charfi MR. Tracheobronchopathia osteochondroplastica: an unusual cause of chronic cough. QJM 2016;109:193-4.

11. Wang L, He B, Chen Q, et al. Delayed diagnosis for primary tracheobronchial amyloidosis. Zhong Nan Da Xue Xue Bao Yi Xue Ban 2015;40:693-6.

12. Jinnur PK, Pannu BS, Boland JM et al. Occult pulmonary lymphangitic carcinomatosis presenting as 'chronic cough' with a normal HRCT chest. Ann Med Surg (Lond) 2016;6:77-80.

13. Miller CP, Firoozan S, Woo EK, et al. Chronic cough: a herald symptom of thoracic aortic aneurysm in a patient with a bicuspid aortic valve. BMJ Case Rep 2014;2014:bcr2014205005.

14. McGarvey LP, Heaney LG, MacMahon J. A retrospective survey of diagnosis and management of patients presenting with chronic cough to a general chest clinic. Int J Clin Pract 1998;52:158-61.

15. Palombini BC, Villanova CA, Araújo E, et al. A pathogenic triad in chronic cough: asthma, postnasal drip syndrome, and gastroesophageal reflux disease. Chest 1999;116:279-84.

16. Chang AB, Van Asperen PP, Glasgow N, et al. Children with chronic cough: when is watchful waiting appropriate? Development of likelihood ratios for assessing children with chronic cough. Chest 2015;147:745-53.

17. Truba O, Rybka A, Klimowicz K, et al. Is a normal chest radiograph sufficient to exclude pulmonary abnormalities potentially associated with chronic cough? Adv Respir Med 2018;86:113-20.

18. Brenner DJ, Hall EJ. Computed tomography--an increasing source of radiation exposure. N Engl J Med 2007;357:2277-84.

19. Berrington de González A, Mahesh M, Kim KP, et al. Projected cancer risks from computed tomographic scans performed in the United States in 2007. Arch Intern Med 2009;169:2071-7.

20. Ohno Y, Koyama H, Seki S, et al. Radiation dose reduction techniques for chest CT: Principles and clinical results. Eur J Radiol 2019;111:93-103.

21. Fuchs TA, Stehli J, Bull S, et al. Coronary computed tomography angiography with model-based iterative reconstruction using a radiation exposure similar to chest X-ray examination. Eur Heart J 2014;35:1131-6.

22. Hu-Wang E, Schuzer JL, Rollison S, et al. Chest CT Scan at Radiation Dose of a Posteroanterior and Lateral Chest Radiograph Series: A Proof of Principle in Lymphangioleiomyomatosis. Chest 2019;155:528-33.

23. Ettinger DS, Wood DE, Aggarwal C, et al. NCCN Guidelines Insights: Non-Small Cell Lung Cancer, Version 1.2020. J Natl Compr Canc Netw 2019;17:1464-72.

24. Maekura T, Tsuyuguchi K, Kimura Y, et al. Clinical study of 29 cases of endobronchial tuberculosis. Kekkaku 2016;91:579-83.

25. Irwin RS, Corrao WM, Pratter MR. Chronic persistent cough in the adult: the spectrum and frequency of causes and successful outcome of specific therapy. Am Rev Respir Dis 1981;123:413-7.

26. Gibson P, Wang G, McGarvey L, et al. Treatment of Unexplained Chronic Cough: CHEST Guideline and Expert Panel Report. Chest 2016;149:27-44.

27. Poe RH, Israel RH, Utell MJ, et al. Chronic cough: bronchoscopy or pulmonary function testing? Am Rev Respir Dis 1982;126:160-162.

28. Decalmer S, Woodcock A, Greaves M, et al. Airway abnormalities at flexible bronchoscopy in patients with chronic cough. Eur Respir J 2007;30:1138-42.

29. Fracchia MS, Diercks G, Cook A, et al. The diagnostic role of triple endoscopy in pediatric patients with chronic cough. Int J Pediatr Otorhinolaryngol 2019;116:58-61.

Cite this article as: $\mathrm{Yu} \mathrm{L}, \mathrm{Xu} \mathrm{X}$, Niu S. Should computed tomography and bronchoscopy be routine examinations for chronic cough? J Thorac Dis 2020;12(9):5238-5242. doi: 10.21037/ jtd-2020-icc-001 